\title{
Sensorineural hearing loss after concurrent chemoradiotherapy in nasopharyngeal cancer patients
}

\author{
Janjira Petsuksiri ${ }^{*}$, Achariyaporn Sermsree ${ }^{1,2}$, Kullathorn Thephamongkhol ${ }^{1}$, Phawin Keskool ${ }^{3}$, Kanthong Thongyai $^{3}$, \\ Yaowalak Chansilpa', Pittayapoom Pattaranutaporn ${ }^{1}$
}

\begin{abstract}
Background: Sensorineural hearing loss (SNHL) is one of the major long term side effects from radiation therapy (RT) in nasopharyngeal cancer (NPC) patients. This study aims to review the incidences of SNHL when treating with different radiation techniques. The additional objective is to determine the relationship of the SNHL with the radiation doses delivered to the inner ear.

Methods: A retrospective cohort study of 134 individual ears from 68 NPC patients, treated with conventional RT and IMRT in combination with chemotherapy from 2004-2008 was performed. Dosimetric data of the cochlea were analyzed. Significant SNHL was defined as $>15 \mathrm{~dB}$ increase in bone conduction threshold at $4 \mathrm{kHz}$ and PTA (pure tone average of $0.5,1,2 \mathrm{kHz}$ ). Relative risk (RR) was used to determine the associated factors with the hearing threshold changes at $4 \mathrm{kHz}$ and PTA.
\end{abstract}

Results: Median audiological follow up time was 14 months. The incidence of high frequency $(4 \mathrm{kHz}) \mathrm{SNHL}$ was $44 \%$ for the whole group (48.75\% in the conventional RT, 37\% with IMRT). Internal auditory canal mean dose of $>$ $50 \mathrm{~Gy}$ had shown a trend to increase the risk of high frequency SNHL (RR 2.02 with 95\% Cl 1.01-4.03, $p=0.047$ ).

Conclusion: IMRT and radiation dose limitation to the inner ear appeared to decrease SNHL.

\section{Background}

Radiation therapy (RT) is the standard treatment for nasopharyngeal cancer (NPC) patients as a result of the relative radiosensitivity, deep location and the close proximity to the normal critical structures. High dose $\mathrm{RT}$ of $\geq 66$ Gy in combination with chemotherapy has yielded a 5-year locoregional control for more than $80 \%$ of the patients with locally advanced disease [1-3]. Consequently, RT produces undesirable side effects on the adjacent organs. In addition to xerostomia, sensorineural hearing loss (SNHL), resulting from the cochlea damage, is one of the major long term side effects which impacts the patients' quality of life. With modern conformal radiation techniques, the incidence of radiation induced SNHL is expected to decline, due to a better

\footnotetext{
* Correspondence: sijps@mahidol.ac.th

'Division of Radiation Oncology, Faculty of Medicine Siriraj Hospital,

2 Prannok Rd, Bangkoknoi, Bangkok, Thailand

Full list of author information is available at the end of the article
}

visualization of the organs on the planning $\mathrm{CT}$ images and a better capability to spare the cochlea with a mean dose < 40-50 Gy [4-7].

This retrospective analytic study aims to report the incidences of SNHL of NPC patients receiving chemoradiotherapy with conventional RT comparing with intensity modulated radiation therapy (IMRT). To our knowledge, this study is the first one to compare hearing status between conventional RT and IMRT for NPC patients. As most earlier studies had some disagreement about the cochlea contouring for dose volume analysis, the further aim of this study is to evaluate radiation doses in each specific part of the inner ear [cochlea, inner ear (cochlea and vestibule) and internal auditory canal (IAC)] in correlation with the incidences of SNHL.

\section{Methods}

The medical records, including radiation dosimetric data and audiological assessment of the 507 NPC patients

\section{Ciomed Central}


receiving definitive $\mathrm{RT}$ at the division of Radiation Oncology, Siriraj Hospital from January 2004 to December 2008 were retrospectively reviewed under the approval of the Siriraj institutional review board.

Two hundred and four NPC patients with T1-T4, N0-N3, M0 diseases (according to AJCC 1997 staging system) who completed RT courses with either conventional RT or IMRT with baseline pre RT audiograms were included. Patients were excluded from the study when they had no medical records, no post RT audiograms, or not completed RT. Patients who had tumor invasion into the inner ear or had a recurrent disease were also excluded. No patients were excluded because of a hearing impairment during RT. Patients who had severe hearing impairment (pure tone average: PTA, at $0.5,1,2 \mathrm{kHz}>50 \mathrm{~dB}$ in both ears) on pre RT audiograms were excluded. Each individual ear was evaluated independently for radiation doses and hearing status. Ultimately, 134 individual ears with intact hearing status were included for data analysis (Figure 1).

\section{Radiation therapy}

The radiation technique has changed from conventional RT (before 2007) to IMRT (since 2007) due to machine evolution at our institute. After the start of the IMRT era, all patients with a curative aim were treated with IMRT. Therefore, 41 patients were treated with conventional RT and 27 patients were treated with IMRT. For the conventional $\mathrm{RT}$, radiation was prescribed to a total dose of 66-70 Gy at 2 Gy per fraction, 5 fractions per week. All patients were treated with a Cobalt 60 teletherapy unit. Parallel opposed portals were used for the

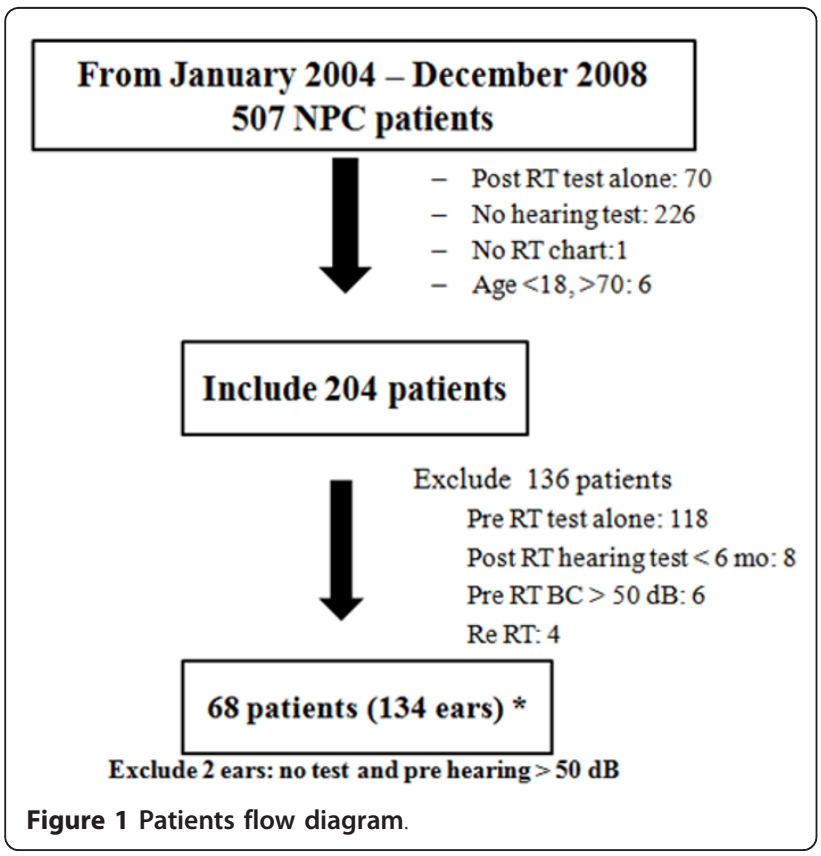

primary tumor site and the upper neck. Spinal cord and brainstem were mostly shielded at the dose of $46 \mathrm{~Gy}$. This conventional field generally included the base of the skull, for which the inner ear was not intentionally protected by the posterior fossa block. The lower neck was routinely treated with the anterior split field.

For IMRT, the target volumes and normal tissue structures were defined by using $\mathrm{CT}$ images. The gross target volume (GTV) consisted of the gross primary tumor and involved lymph nodes as defined by contrast enhancement CT. Generally, clinical target volume (CTV) high risk was defined by adding a $5-\mathrm{mm}$ margin to GTV. A smaller margin ( $3 \mathrm{~mm}$ ) was accepted for the margin that was in close proximity to the critical structures, such as brainstem, optic nerves and optic chiasm. CTV intermediate and low risk regions were contoured according to the RTOG recommendation [8]. Planning target volume (PTV) was defined by adding a $5-\mathrm{mm}$ margin to the CTVs in all dimensions to include setup uncertainties. Radiation doses were prescribed simultaneously to total doses of 66-70 Gy to the high risk region, 59.4-63 Gy to the intermediate-risk region, and 50.4-57 Gy to the low-risk region, in 33-35 fractions. The primary tumor and the upper neck were treated with IMRT. For the lower neck region, either continuing IMRT with the upper neck part or with the anterior spilt field was allowed.

\section{Dose Calculation of the Inner Ear}

Dose calculation of the inner ear was not accessible for patients who received conventional RT. For the patients who were treated with IMRT, dose calculations to the inner ear were evaluated. Initially, the inner ears (cochlea and vestibule) were contoured and constrained (mean doses constraint of 35 Gy with doses accepted at $50 \mathrm{~Gy}$ ) at the time of radiation treatment planning. Each of the inner ear structures was re-contoured (using bone window; window width $=2000 \mathrm{HU}$, window level $=400 \mathrm{HU})$ and reviewed by the authors (JP and AS) as in Figure 2. We defined the inner ear as a combination of the cochlea and vestibule. The purpose of the inner ear delineation was to compare its' dose with the prior studies that defined the inner ear as a cochlea for SNHL evaluation [6,7]. The IAC was contoured to evaluate the radiation doses to the cochlea nerve, which can be affected by radiation. The minimum dose, maximum dose and mean dose were recalculated for each part of the auditory pathway.

\section{Chemotherapy}

Patients with locally advanced disease received concurrent intravenous platinum-based chemotherapy (Cisplatin or Carboplatin). Cisplatin was given with $100 \mathrm{mg} / \mathrm{m}^{2}$ every 3 weeks during the radiation course, followed by 


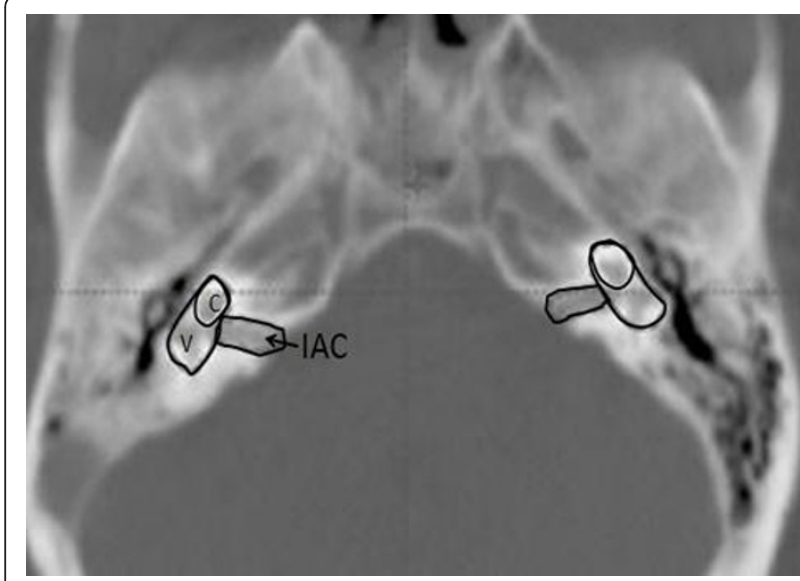

Figure 2 Inner ear contouring. C: Cochlea, V: Vestibule, IAC: internal auditory canal Inner ear $=\operatorname{cochlea}(C)+$ vestibule $(V)$.

Cisplatin $80 \mathrm{mg} / \mathrm{m}^{2}$ at day 1 and 5 -FU $1000 \mathrm{mg} / \mathrm{m}^{2}$ at day 1-4 every 3 weeks. Carboplatin was allowed in patients with poor renal function or were intolerant to Cisplatin. Carboplatin was given in a weekly fashion (AUC 2) during the radiation course, followed by adjuvant Carboplatin (AUC 5 at day 1) in combination with 5 -FU $\left(1000 \mathrm{mg} / \mathrm{m}^{2}\right.$ at day $\left.1-4\right)$ every 3 weeks. Type (Cisplatin or Carboplatin), doses, and cycles of chemotherapy were recorded.

\section{Audiological assessment}

Pre and post RT audiological data were reviewed. The audiograms were ordered routinely for all patients at pre RT and post RT periods by ENT physicians per our hospital's policy. The bone conduction (BC) threshold was measured at $0.5-4 \mathrm{kHz}$ to detect the early SNHL from the cochlea and/or IAC damages. BC threshold at $4 \mathrm{kHz}$ was selected to represent the high frequency loss. The pure tone average (PTA), an average of threshold levels at $0.5 \mathrm{kHz}, 1 \mathrm{kHz}$ and $2 \mathrm{kHz}$, was chosen to reflect the threshold in the low frequency speech range $[9,10]$. Post RT audiograms (at least 6 months after completion of RT) were obtained at various intervals. The most recently performed audiograms were used for the analysis. Hearing threshold changes were determined by comparing with their pre RT baselines. As per the American Speech and Hearing Association guidelines, significant SNHL was defined as a $\geq 10 \mathrm{~dB}$ increase at two consecutive frequencies or $\geq 15 \mathrm{~dB}$ at one frequency. Hence, the cut-off point of $\geq 15 \mathrm{~dB}$ increase from baseline in $\mathrm{BC}$ threshold at $4 \mathrm{kHz}$ was used as a criterion for SNHL in this study.

The incidences of otitis media effusion (OME) and tympanic membrane perforation were documented at baseline and follow up. Influences from age, chemotherapy, OME, co-morbidities (DM and hypertension), radiation techniques and the radiation doses on the change of $\mathrm{BC}$ thresholds were assessed.

\section{Statistical methods}

The statistics program STATA, version 8 was employed for data analysis. Relative risk (RR) with $95 \%$ confidential interval (CI) was used to determine the relationship between the possible associated factors and the threshold changes at $4 \mathrm{kHz}$ and PTA. We tested the null hypothesis as to whether the relative risk was equal to 1 by calculating the chi-square test statistics.

\section{Results}

From January 2004 to December 2008, 68 patients (41 patients with conventional RT, 27 patients with IMRT) were enrolled for the hearing analysis. The patients' characteristics were shown in Table 1 . Sixty six patients (97.1\%) received concurrent chemoradiotherapy and only 2 patients (2.9\%) received RT alone.

\section{Radiation doses to the inner ear}

For 41 patients who received conventional RT, dosimetric data were not available. For 27 patients who received IMRT, 54 ears were re-analyzed. Mean doses to the cochlea, inner ear and IAC were 51.02 Gy (range 25.09 - 75.54), 45.32 Gy (range 19.86-75.55) and 50.51 Gy (range 27.75-73.29), respectively.

Table 1 Patient characteristics (Total 134 individual ears, 68 patients)

\begin{tabular}{lc}
\hline Characteristics & Value (68 patients) \\
\hline Age (18-70 years old) & Median 47.5 years old \\
$\leq 50$ & $44(65 \%)$ \\
$>50$ & $24(35 \%)$ \\
Co-morbidities (patients) & $14(20.6 \%)$ \\
DM and/or Hypertension & $54(79.4 \%)$ \\
No co-morbidities & \\
Pre RT otitis media (ears) & $34(25.4 \%)$ \\
Yes & $71(53 \%)$ \\
No & $29(21.6 \%)$ \\
No data & \\
Post RT otitis media (ears) & $31(23.1 \%)$ \\
Yes & $93(69.4 \%)$ \\
No & $10(7.5 \%)$ \\
No data & \\
Tumor stage & $15(22.1 \%)$ \\
I/II & $53(77.9 \%)$ \\
III/IV & \\
Pathology (WHO 2005) & $24(35.2 \%)$ \\
WHO type 1 (SCC, keratinized) & $4(5.9 \%)$ \\
WHO type 2 (SCC, non-keratinized) & $38(55.9 \%)$ \\
WHO type 2.2 (Undifferentiated) & $2(3 \%)$ \\
Others & \\
\hline
\end{tabular}




\section{Chemotherapy}

Chemotherapy was given to $97 \%$ of the patients $(66 / 68$ patients). Most of the patients received concurrent chemoradiotherapy followed by adjuvant chemotherapy. Sixty two patients received Cisplatin, while 4 patients received Carboplatin. The total accumulative doses of Cisplatin ranged from $120 \mathrm{mg}$ to $980 \mathrm{mg}$ (median dose $689 \mathrm{mg}$, mean dose $639 \pm 233 \mathrm{mg}$ ). Carboplatin accumulative doses ranged from $200 \mathrm{mg}$ to $2100 \mathrm{mg}$ (median dose $980 \mathrm{mg}$, mean $988 \pm 670 \mathrm{mg}$ ).

\section{Treatment outcomes}

Median follow up time for all patients was 27.5 months (range 8-65 months). At the end of the study, 13 out of 68 patients were lost to follow up. The 2 year-progression free survival of this study group was $76.4 \%$ with a 2 year locoregional control of $88.5 \%$.

\section{Audiological assessment and the incidences of post radiation $\mathrm{SNHL}$}

Pre RT audiograms demonstrated that $65.5 \%$ of the ears $(88 / 134$ ears) were normal or had mild BC hearing losses $(16-25 \mathrm{~dB})$ at $4 \mathrm{kHz}$. At PTA, $91 \%$ of the ears (122/134 ears) were normal or had mild hearing losses.

Post RT audiograms were performed at different follow up intervals. The median follow up time of audiological assessment for all 68 patients was 14 months (range 6-43 months). Median audiological follow up times for conventional RT and IMRT groups were 15 months (range 6-43 months) and 13 months (range 629 months), respectively. For total of 68 patients (134 ears), the incidence of SNHL at high frequency $(4 \mathrm{kHz})$ was $52.9 \%$ (unilateral loss 13/68 patients, bilateral loss $23 / 68$ patients). At PTA, the incidence of SNHL was $10.3 \%$ (unilateral loss $6 / 68$ patients, bilateral loss $1 / 68$ patients). For individual ear evaluation, the incidences of SNHL were $44 \%$ (59/134 ears) and 6\% (8/134 ears) at 4 $\mathrm{kHz}$ and PTA, respectively.

\section{Factors associated with the incidences of SNHL Radiation techniques}

With conventional RT, the incidences of SNHL were $48.75 \%(39 / 80$ ears) at $4 \mathrm{kHz}$ and $5 \%(4 / 80$ ears $)$ at PTA, respectively. With IMRT, the incidences of SNHL were $37 \%(20 / 54$ ears) at $4 \mathrm{kHz}$ and $7.4 \%$ (4/54 ears) at PTA, respectively.

\section{Radiation doses to the cochlea, inner ear, and IAC}

Mean radiation doses to the cochlea, inner ear and IAC in this study were about $50 \mathrm{~Gy}, 45 \mathrm{~Gy}$ and $50 \mathrm{~Gy}$, respectively. The authors then evaluated the incidences of SNHL based upon the mean radiation doses to each inner ear structure as shown in Table 2.

On univariate analysis; IMRT, cochlea mean dose $\leq 50$ Gy, inner ear mean doses $\leq 45$ Gy and IAC mean dose
Table 2 The incidences of SNHL and the inner ear mean radiation dose (IMRT)

\begin{tabular}{cccc}
\hline Mean radiation doses & $\begin{array}{c}\text { Total } \\
\text { 54 ears }\end{array}$ & $\begin{array}{c}\text { SNHL at 4 Hz } \\
\text { (ears) }\end{array}$ & $\begin{array}{c}\text { SNHL at PTA } \\
\text { (ears) }\end{array}$ \\
\hline Cochlea mean dose & & & \\
$\leq 50$ Gy & 24 & $6 / 24(25 \%)$ & $0 / 24(0 \%)$ \\
$>50$ Gy & 30 & $14 / 30(46.67 \%)$ & $4 / 30(13.3 \%)$ \\
\hline Inner ear mean dose & & & \\
$\leq 45$ Gy & 29 & $8 / 29(27.59 \%)$ & $0 / 29(0 \%)$ \\
$>$ 45 Gy & 25 & $12 / 25(48 \%)$ & $4 / 25(16 \%)$ \\
\hline IAC mean dose & & & \\
$\leq 50$ Gy & 31 & $8 / 31(25.81 \%)$ & $0 / 31(0 \%)$ \\
$>50$ Gy & 23 & $12 / 23(52.17 \%)$ & $4 / 23(17.4 \%)$ \\
\hline
\end{tabular}

$\leq 50$ Gy appeared to have lower incidences of SNHL at high frequency $(4 \mathrm{kHz})$. The other associated factors, including Cisplatin doses, OME, age and co-morbidities of the patients were not demonstrated to affect the incidence of SNHL (Figure 3). At PTA, there was no significant factor affecting the incidence of SNHL (Figure 4).

Based on the literatures reviewed, most studies reported that the incidences of SNHL were impacted by mean cochlea doses in the range of $45-50$ Gy $[4,5,7,11]$. We therefore did not re-explore the data as quantitative continuous variables. Instead, we re-validated the known cut-off point starting at $50 \mathrm{~Gy}$, which was actually the mean cochlea dose in our study. The lowermost cut-off level at 45 Gy was chosen for analysis [7]. The data showed that the RR for mean dose of $>45$ Gy was 1.77 (95\% CI 0.82-4.24) at $4 \mathrm{kHz}$, compared to dose $\leq 45 \mathrm{~Gy}$. This analysis showed that the incidence of SNHL was not significantly changed when mean cut-off doses to the cochlea decreased from 50 to $45 \mathrm{~Gy}$.

Based on the cochlea nerve tolerance of $54 \mathrm{~Gy}$, we then explored the optimal radiation threshold to the IAC by creating a hypothesis with a cut-off point of

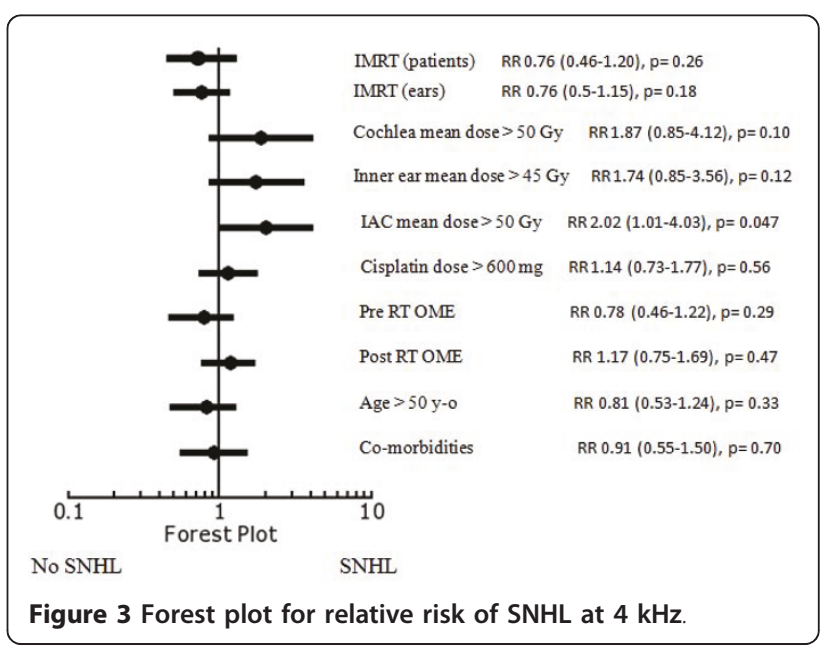




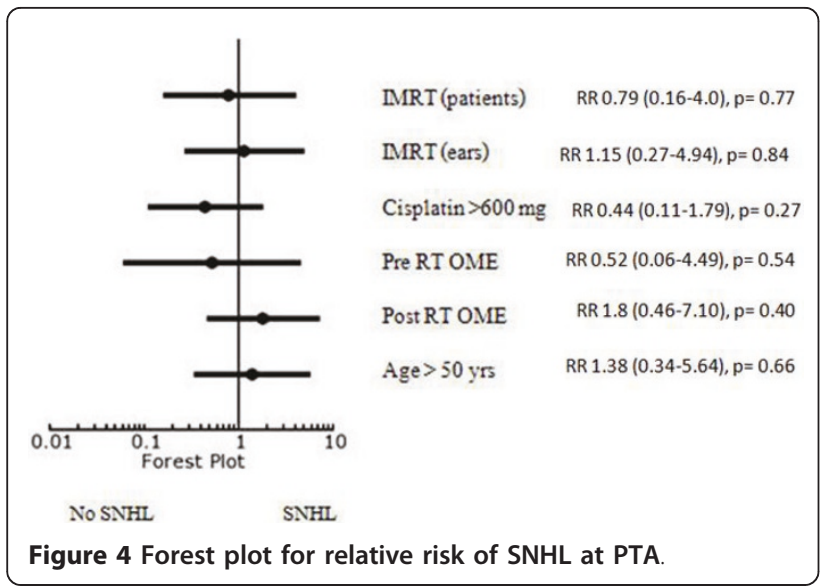

54 Gy. The data showed that the RR for a mean dose $>54$ Gy was 2.25 (95\% CI 1.14-4.17) compared to a mean dose $\leq 54 \mathrm{~Gy}$ at $4 \mathrm{~Hz}$.

As radiation techniques had a potential effect on SNHL, we had analyzed the effect of IMRT on different variables with bivariate analysis. The bivariate analysis demonstrated that IMRT tended to decrease SNHL in younger patients ( $\leq 50$ years old) or healthy patients without medical co-morbidities (DM and/or hypertension) (Table 3).

As NPC patients required Cisplatin chemotherapy to ensure the local and distant control, SNHL was potentially worse when combined with high radiation doses to the hearing structures. The authors then performed a bivariate analysis to evaluate the effects of Cisplatin on radiation dose levels for each inner ear structure. An accumulative Cisplatin dose of $>600 \mathrm{mg}$ was used in this analysis since the mean Cisplatin dose delivered was about $600 \mathrm{mg}$ in our study. The data demonstrated that in patients who received higher dose of Cisplatin ( $>600$ $\mathrm{mg}$ ), the incidences of SNHL tended to be higher if they received mean radiation dose of $>50$ Gy to the cochlea and $>45$ Gy to the inner ear (Table 4).

Table 3 Bivariate analysis (Effect of IMRT on different variables)

\begin{tabular}{ccc}
\hline Factors & Relative risk & $\begin{array}{c}\text { Test for } \\
\text { homogeneity }\end{array}$ \\
\hline $\begin{array}{c}\text { Age (years old) } \\
>50\end{array}$ & $1.00(95 \% \mathrm{Cl} 0.49-2.10)$ & $\mathrm{p}=0.40$ \\
$\leq 50$ & $0.68(95 \% \mathrm{Cl} 0.39-1.18)$ & \\
\hline $\begin{array}{c}\text { Cisplatin (total dose, mg) } \\
>600 \mathrm{mg}\end{array}$ & $0.94(95 \% \mathrm{Cl} 0.59-1.49)$ & $\mathrm{p}=0.57$ \\
$\leq 600 \mathrm{mg}$ & $0.70(95 \% \mathrm{Cl} 0.28-1.73)$ & \\
\hline $\begin{array}{c}\text { Co-morbidities } \\
\text { Yes }\end{array}$ & $1.11(95 \% \mathrm{Cl} 0.45-2.78)$ & $\mathrm{p}=0.36$ \\
No & $0.69(95 \% \mathrm{Cl} 0.43-1.12)$ & \\
\hline
\end{tabular}

Table 4 Bivariate analysis of Cisplatin effect on radiation dose levels

\begin{tabular}{|c|c|c|}
\hline Factors & Relative risk & $\begin{array}{c}\text { Test for } \\
\text { homogeneity }\end{array}$ \\
\hline Cochlea mean dose (Gy) & & $p=0.21$ \\
\hline$>50$ & $2.1(95 \% \mathrm{Cl} 0.62-7.15)$ & \\
\hline$\leq 50$ & $0.63(95 \%$ Cl 0.15-2.67) & \\
\hline Inner ear mean dose (Gy) & & $p=0.14$ \\
\hline$>45$ & $3.06(95 \%$ Cl 0.51-18.33) & \\
\hline$\leq 45$ & 0.67 (95\%Cl 0.2-2.19) & \\
\hline IAC mean dose (Gy) & & $p=0.89$ \\
\hline$>50$ & 1.33 (95\% Cl 0.47-3.78) & \\
\hline$\leq 50$ & 1.18 (95\% Cl 0.29-4.81) & \\
\hline
\end{tabular}

\section{Discussion}

Radiation induced SNHL has been recognized as an important adverse effect which generally develops 6 to 24 months after radiation treatment and may progress to complete deafness $[10,12]$. The inner ear is the most susceptible organ for a durable long term SNHL. The etiologies of RT induced SNHL are vascular insufficiency, reduced number of capillaries, degeneration of endotheliocytes in vessels, loss of cells in the organ of Corti, atrophy and degeneration of the stria vascularis, and atrophy of the spiral ganglion cells and the cochlea nerve $[13,14]$. This damage is more prominent to the outer hair cells in the basal turn of the cochlea, which is responsible for transduction of higher frequency sound and a clinically significant SNHL at a higher frequency $(>2 \mathrm{~Hz})$ might occur.

The incidences of radiation induced SNHL were reported in the range of $0-65 \%$ with various radiation techniques (Table 5). Our study demonstrated that the incidences of SNHL were 44\% (59/134 ears) at high frequency $(4 \mathrm{kHz})$ and $6 \%(8 / 134$ ears $)$ at PTA for the whole population. Each study, however, was performed and evaluated with different criteria and follow up times.

The median follow up time (14 months) for audiological assessment in this study was rather shorter than the other studies. Nonetheless, radiation induced ototoxicity is typically evident at 6-12 months after completion of radiation therapy [4]. Transient SNHL might occur up to $41 \%$ of the patients as reported by Ho et al [12]. This study was not able to evaluate the transient hearing loss because of its retrospective design which was based upon different follow up times.

The hospital's policy is to routinely perform the audiological assessment for all NPC patients. However, a number of patients in our study did not complete the audiological tests. We recognized that the completeness of audiometric evaluation for every patient would be challenging in the absence of a prospective clinical trial. In this study, we compared the differences of pre and 
Table 5 Criteria and radiation doses to the cochlea in correlation with the incidences of SNHL

\begin{tabular}{|c|c|c|c|c|}
\hline Study & RT & Criteria & Doses to cochlea & $\begin{array}{l}\text { Median follow up } \\
\text { \& SNHL (per ear) }\end{array}$ \\
\hline Kwong et al[10] & $\begin{array}{l}\text { Conv RT + chemo } \\
\text { (227 ears) }\end{array}$ & $>15 \mathrm{~dB}$ at each frequency & not defined & $\begin{array}{l}30 \text { months } \\
24.2 \%\end{array}$ \\
\hline Oh et al [19] & $\begin{array}{l}\text { Conv RT + chemo } \\
\text { (48 ears) }\end{array}$ & $\begin{array}{l}>15 \mathrm{~dB} \text { at } \\
4 \mathrm{kHz} \text { and PTA }\end{array}$ & mean inner ear dose $66.2 \pm 6.2$ & $\begin{array}{l}1 \text { year } \\
29.2 \%\end{array}$ \\
\hline Ho et al [12] & $\begin{array}{l}\text { Conv RT + chemo } \\
\text { (526 ears) }\end{array}$ & $\begin{array}{l}>10 \mathrm{~dB} \text { at } \\
4 \mathrm{kHz} \text { and PTA }\end{array}$ & $\begin{array}{l}\text { estimated } \\
\text { 70-91 Gy, 2.5-3.5 Gy/F }\end{array}$ & $\begin{array}{l}4.5 \text { years, } \\
4 \mathrm{kHz} 60 \% \\
\text { PTA } 18 \% \\
\end{array}$ \\
\hline Chan et al [5] & $\begin{array}{l}\text { Conf RT vs } \\
\text { Conf RT }+ \text { chemo } \\
\text { (170 ears) }\end{array}$ & $\begin{array}{l}>15 \mathrm{~dB} \text { at } \\
4 \mathrm{kHz}\end{array}$ & $\begin{array}{l}\text { mean cochlea dose } \\
\text { 33-71.7 Gy }\end{array}$ & $\begin{array}{l}24 \text { months } \\
33.3 \% \text { vs } 55 \% \\
\text { (Conf RT vs } \\
\text { Conf RT+ chemo) }\end{array}$ \\
\hline Chen et al.[4] & $\begin{array}{l}\text { Conf RT+ chemo } \\
\text { (44 ears) }\end{array}$ & $\begin{array}{l}>20 \mathrm{~dB} \text { at one frequency } \\
>10 \mathrm{~dB} \text { at two frequencies }\end{array}$ & $28.4-70.0 \mathrm{~Gy}$ & $\begin{array}{l}29 \text { months } \\
57 \%\end{array}$ \\
\hline Our study & $\begin{array}{l}\text { Conv RT +chemo } \\
\text { vs IMRT+ chemo } \\
\text { (134 ears, } 68 \text { patients) }\end{array}$ & $\begin{array}{l}>15 \mathrm{db} \text { loss at } \\
4 \mathrm{kHz} \text { and PTA }\end{array}$ & Mean cochlea dose 25.09-75.54 Gy (IMRT) & $\begin{array}{l}14 \text { months } \\
4 \mathrm{kHz} \\
\text { Conv } 48.75 \% \\
\text { IMRT 37\% } \\
\text { PTA Conv 5\% } \\
\text { IMRT } 7.4 \%\end{array}$ \\
\hline
\end{tabular}

Conv RT = Conventional radiation therapy Conf RT = Conformal radiation therapy.

post RT audiograms rather than using the specific hearing threshold to justify the SNHL. We also excluded the patients who had only post RT audiograms. This should diminish the bias from patients who performed audiological exams because of having hearing impairment post RT.

The prior studies included only patients who completed the audiological assessment. This would potentially alter the incidence of SNHL in a certain number of patients who never performed the audiological exams. Also, the usage of contralateral ear as a baseline could create some inconsistency of the results $[4,15,16]$. Thus, we assumed that the results of our study would be adequate to report the incidence of SNHL although we understood the weakness of retrospective data.

With different radiation techniques, IMRT was found to have fewer incidence of SNHL when compared to the conventional RT (37\% vs $48.75 \%$ ). There was a trend to decrease the incidences of SNHL with IMRT in our study (RR of 0.76 with 95\% CI 0.5-1.15, favouring IMRT). The former studies for NPC treatment had not directly compared the incidences of SNHL between conventional technique and conformal techniques. By indirect comparison among studies, the incidences of SNHL with the conformal techniques were not consistently lower than the conventional technique as shown in Table 5. The delineation of the normal structures and radiation dose constraint are very important in IMRT planning. IMRT potentially provides higher radiation doses to the cochlea than three dimensional conformal radiation technique, or even more than conventional $\mathrm{RT}$, if the cochlea is not intentionally avoided [17].
In this study, we had delineated the inner ear into the cochlea and inner ear as there was some disagreement of cochlea delineation among the earlier studies $[5,7]$. Because of the tiny volume of the cochlea, target delineation is essential for dose volume analysis. Especially, its location is in the high dose gradient of the IMRT.

The results from our study demonstrated that the incidence of high frequency SNHL tended to be increased when mean dose delivered to the cochlea was $>50$ Gy. Earlier studies suggested that the incidences of SNHL were increased with mean cochlea doses $>45-50$ Gy $[4,5,7,11]$. However, our exploratory analysis showed that the incidence of SNHL was not significantly changed when mean cut-off doses to the cochlea decreased from 50 to 45 Gy. Therefore, our study suggested that the mean cochlea dose of $50 \mathrm{~Gy}$ should be reasonable since the excessive dose constraint to the cochlea would potentially compromise the nearby targets coverage.

Apart from the cochlea, the IAC should be concerned as the cochlea nerve traverses through the canal entering into the brainstem. The SNHL due to a retrocochlea (cochlea nerve) damage may occur, although, this was relatively rare compared to the cochlea damage [18]. IMRT could deliver higher doses up to 66 Gy to the IAC if the IAC was not specified as the organ at risk [19]. This study demonstrated that the IAC mean doses > 50 Gy showed a trend to increase the incidence of high frequency $(4 \mathrm{kHz})$ SNHL (RR 2.02 with 95\% CI 0.99-4.13). IAC dose limitation was also crucial as the patients who developed SNHL from cochlea nerve 
damage would not obtain any benefits from using a hearing aid or even a cochlea implantation.

Our study revealed the lower incidence (10.3\%) of low frequency SNHL (PTA). This concurred with the other series, as the high frequency $(>4 \mathrm{kHz})$ would be the earliest sign for damage at the outer hair cells in the basal turn of the cochlea [19].

Another coexisting factor for high frequency SNHL was a combination of Cisplatin chemotherapy with RT from a synergistic effect to the cochlea $[4,5,15,20]$. Some series reported that $600 \mathrm{mg} / \mathrm{m}^{2}$ [21] or total dose of $1,050 \mathrm{mg}$ [22] of Cisplatin increased the incidences of high frequency SNHL. As most of the patients in this study had locally advanced disease and received a combination of chemotherapy, the effect of Cisplatin to SNHL could not be evaluated directly. There was no apparent increase in the incidence of SNHL with a total accumulation dose of $>600 \mathrm{mg}$ in this study. However, a further bivariate analysis revealed that dose limitation to the cochlea (<50 Gy) and inner ear ( $<45 \mathrm{~Gy}$ ) would potentially protect SNHL in patients who received Cisplatin chemotherapy to an accumulative dose of $>600 \mathrm{mg}$.

For the other associated factors, Kwong et al reported the association of age, sex, and post RT serous otitis media as significant prognostic factors for persistent SNHL on multivariate analysis [10]. Nonetheless, this study could not demonstrate any relationship among age, evidence of otitis media, and/or medical co-morbidities with the incidence of SNHL.

Lastly, the inter-fraction setup uncertainties for very small structures are crucial. Radiation dose evaluation on the computer planning would be only the estimation of the actual dose delivered to the tiny inner ear during the radiation course.

\section{Conclusion}

Apparently, radiation therapy produces relatively high incidences of high frequency SNHL. The severities of the damage are increased with higher radiation doses delivered to the inner ear structures. Mean radiation dose constraint of 50 Gy to the cochlea and IAC showed a trend to decrease the incidences of SNHL, especially in patients who received combination of Cisplatin chemotherapy. Normal structures delineation and radiation dose constraint with modern radiation techniques are crucial to diminish the long term SNHL and enhance the quality of life in addition to insuring survival from the cancer.

\section{Acknowledgements}

The authors want to thank all Siriraj Radiation Oncology medical and physic staffs for their productive comments and radiation doses analysis. This study was supported by the Siriraj Research Development Fund.

\section{Author details}

${ }^{1}$ Division of Radiation Oncology, Faculty of Medicine Siriraj Hospital, 2 Prannok Rd, Bangkoknoi, Bangkok, Thailand. ${ }^{2}$ Department of Radiation Oncology, Ubonratchathani Cancer Center, Ubonratchathani, Thailand. ${ }^{3}$ Department of Oto-Rhino-Laryngology, Faculty of Medicine Siriraj Hospital, 2 Prannok Rd, Bangkoknoi, Bangkok, Thailand.

\section{Authors' contributions}

JP designed the study, analysed the data and prepared the manuscript. AS carried out data collection, data analysis and helped to draft the manuscript. $K T$ participated in the design of the study and performed the statistical analysis. PK participated in its design and hearing data evaluation. KT participated in hearing data evaluation. YC participated in its design and helped to draft the manuscript. PP participated in its design and helped to draft the manuscript. All authors read and approved the final manuscript.

\section{Authors' information}

JP is an assistant professor in radiation oncology, focusing in head and neck cancer treatment. AS is a former radiation oncology resident. She is now a radiation oncologist at the regional cancer centre. $K T$ is an instructor in radiation oncology, also a research facilitator in radiation oncology field. PK is an assistant professor in oto-rhino-laryngology, focusing in head and neck cancer surgery. KT is an instructor in oto-rhino-laryngology, specialized in otology. YC is an associated professor in radiation oncology. PP is a professor in radiation oncology, and a head of radiation oncology division.

\section{Competing interests}

The authors declare that they have no competing interests.

Received: 18 October 2010 Accepted: 20 February 2011 Published: 20 February 2011

\section{References}

1. Al-Sarraf M, LeBlanc M, Giri PG, Fu KK, Cooper J, Vuong T, Forastiere AA, Adams G, Sakr WA, Schuller DE, et al: Chemoradiotherapy versus radiotherapy in patients with advanced nasopharyngeal cancer: phase III randomized Intergroup study 0099. J Clin Oncol 1998, 16(4):1310-1317.

2. Wee J, Tan EH, Tai BC, Wong HB, Leong SS, Tan T, Chua ET, Yang E, Lee KM, Fong KW, et al: Randomized trial of radiotherapy versus concurrent chemoradiotherapy followed by adjuvant chemotherapy in patients with American Joint Committee on Cancer/International Union against cancer stage III and IV nasopharyngeal cancer of the endemic variety. J Clin Oncol 2005, 23(27):6730-6738.

3. Huncharek M, Kupelnick B: Combined chemoradiation versus radiation therapy alone in locally advanced nasopharyngeal carcinoma: results of a meta-analysis of 1,528 patients from six randomized trials. Am J Clin Oncol 2002, 25(3):219-223.

4. Chen WC, Jackson A, Budnick AS, Pfister DG, Kraus DH, Hunt MA, Stambuk H, Levegrun S, Wolden SL: Sensorineural hearing loss in combined modality treatment of nasopharyngeal carcinoma. Cancer 2006, 106(4):820-829.

5. Chan SH, Ng WT, Kam KL, Lee MC, Choi CW, Yau TK, Lee AW, Chow SK: Sensorineural hearing loss after treatment of nasopharyngeal carcinoma: a longitudinal analysis. Int J Radiat Oncol Biol Phys 2009, 73(5):1335-1342.

6. Herrmann F, Dorr W, Muller R, Herrmann T: A prospective study on radiation-induced changes in hearing function. Int $J$ Radiat Oncol Biol Phys 2006, 65(5):1338-1344.

7. Pan CC, Eisbruch A, Lee JS, Snorrason RM, Ten Haken RK, Kileny PR: Prospective study of inner ear radiation dose and hearing loss in headand-neck cancer patients. Int I Radiat Oncol Biol Phys 2005, 61(5):1393-1402.

8. Lee N, Harris J, Garden AS, Straube W, Glisson B, Xia P, Bosch W, Morrison WH, Quivey J, Thorstad W, et al: Intensity-modulated radiation therapy with or without chemotherapy for nasopharyngeal carcinoma: radiation therapy oncology group phase II trial 0225. J Clin Oncol 2009, 27(22):3684-3690.

9. Raaijmakers E, Engelen AM: Is sensorineural hearing loss a possible side effect of nasopharyngeal and parotid irradiation? A systematic review of the literature. Radiother Oncol 2002, 65(1):1-7.

10. Kwong DL, Wei WI, Sham JS, Ho WK, Yuen PW, Chua DT, Au DK, Wu PM, Choy DT: Sensorineural hearing loss in patients treated for 
nasopharyngeal carcinoma: a prospective study of the effect of radiation and cisplatin treatment. Int J Radiat Oncol Biol Phys 1996, 36(2):281-289.

11. Bhandare N, Jackson A, Eisbruch A, Pan CC, Flickinger JC, Antonelli P, Mendenhall WM: Radiation therapy and hearing loss. Int I Radiat Oncol Biol Phys 2010, 76(3 Suppl):S50-57.

12. Ho WK, Wei WI, Kwong DL, Sham JS, Tai PT, Yuen AP, Au DK: Long-term sensorineural hearing deficit following radiotherapy in patients suffering from nasopharyngeal carcinoma: A prospective study. Head Neck 1999, 21(6):547-553.

13. Jereczek-Fossa BA, Zarowski A, Milani F, Orecchia R: Radiotherapy-induced ear toxicity. Cancer Treat Rev 2003, 29(5):417-430.

14. Low WK, Tan MG, Chua AW, Sun L, Wang DY: 12th Yahya Cohen Memorial Lecture: The cellular and molecular basis of radiation-induced sensorineural hearing loss. Ann Acad Med Singapore 2009, 38(1):91-94.

15. Bhandare N, Antonelli PJ, Morris CG, Malayapa RS, Mendenhall WM: Ototoxicity after radiotherapy for head and neck tumors. Int I Radiat Oncol Biol Phys 2007, 67(2):469-479.

16. Honore HB, Bentzen SM, Moller K, Grau C: Sensori-neural hearing loss after radiotherapy for nasopharyngeal carcinoma: individualized risk estimation. Radiother Oncol 2002, 65(1):9-16.

17. Hitchcock YJ, Tward JD, Szabo A, Bentz BG, Shrieve DC: Relative contributions of radiation and cisplatin-based chemotherapy to sensorineural hearing loss in head-and-neck cancer patients. Int I Radiat Oncol Biol Phys 2009, 73(3):779-788.

18. Low WK, Burgess R, Fong KW, Wang DY: Effect of radiotherapy on retrocochlear auditory pathways. Laryngoscope 2005, 115(10):1823-1826.

19. Oh YT, Kim CH, Choi JH, Kang SH, Chun M: Sensory neural hearing loss after concurrent cisplatin and radiation therapy for nasopharyngeal carcinoma. Radiother Oncol 2004, 72(1):79-82.

20. Low WK, Toh ST, Wee J, Fook-Chong SM, Wang DY: Sensorineural hearing loss after radiotherapy and chemoradiotherapy: a single, blinded, randomized study. J Clin Oncol 2006, 24(12):1904-1909.

21. Skinner R, Pearson AD, Amineddine HA, Mathias DB, Craft AW: Ototoxicity of cisplatinum in children and adolescents. Br J Cancer 1990, 61(6):927-931.

22. Zuur CL, Simis YJ, Lansdaal PE, Hart AA, Rasch CR, Schornagel JH, Dreschler WA, Balm AJ: Risk factors of ototoxicity after cisplatin-based chemo-irradiation in patients with locally advanced head-and-neck cancer: a multivariate analysis. Int I Radiat Oncol Biol Phys 2007, 68(5):1320-1325.

doi:10.1186/1748-717X-6-19

Cite this article as: Petsuksiri et al:: Sensorineural hearing loss after concurrent chemoradiotherapy in nasopharyngeal cancer patients. Radiation Oncology 2011 6:19.

\section{Submit your next manuscript to BioMed Central and take full advantage of:}

- Convenient online submission

- Thorough peer review

- No space constraints or color figure charges

- Immediate publication on acceptance

- Inclusion in PubMed, CAS, Scopus and Google Scholar

- Research which is freely available for redistribution

Submit your manuscript at www.biomedcentral.com/submit 